\title{
CHEMICAL ACTIVATION EFFECT ON THE MECHANICAL RESPONSE OF MORTARS BASED ON DUNE SAND
}

\author{
Djelloul LADJEL ${ }^{1}$, Moncef ZAIRI ${ }^{1}$, \\ Larbi BELAGRAA ${ }^{2 *}$ \\ 1 Ecole d'Ingénieurs de SFAX, (laboratoire eau, énergie et Environnement), Sfax, 3000, Tunisia \\ 2 Department of civil Engineering, Faculty of Technology, Med Boudiaf University of M'sila, M'sila, \\ 28000 , Algeria
}

\begin{abstract}
The main qualities sought for a mortar are usually; the high compactness, good sealing or impermeability, better mechanical strength and long-term durability. The different methods of accelerating setting and hardening of the mortar as well as the desired characteristics are of great importance with regard to the use of mortars and their different applications in civil engineering. This work is a contribution to improving the properties of mortars at fresh and hardened state by different activation techniques in particular chemical alkaline activators method. The properties of chemically activated mortars using alkaline solutions $(\mathrm{KOH}$ and $\mathrm{NaOH})$ at dosages of 0,2 and $4 \%$ was investigated in this experimental program using a based cement matrix with dune sand and blended cement type CEM II/ B grade 42. The results obtained showed the beneficial effect of the chemical activation modes mainly, an improvement of the mechanical response (compressive strength) at young age and in the long term.
\end{abstract}

Keywords: mortar, chemical activation, alkaline solutions, hardening; mechanical strength

\section{INTRODUCTION}

Portland cement is the most commonly used latent hydraulic binder for mortars and concretes formulation. The factors determining the hydraulicity of portland cements are: the vitreous state (amorphous texture), the hydraulic index and the mineralogical composition. Moreover, the latent property of hydration of Ordinary Portland cement (OPC) can

\footnotetext{
* Corresponding author: Lbelagraa@yahoo.fr (L. Belagraa)
}

doi: $10.37190 / \mathrm{msc} 202705$ 
be demonstrated by measuring the degree of hydration which, in turn, is determined either by the analysis of the residual reagents, the determination of the amount of non-evaporable mixing water, the content of free lime present in the cement, the percentage of free gypsum, the measurement of the heat of hydration (Vénuat 1969; Vornovitch et al. 1975; Barbarulo 2002). The latent property of OPC hydration confirms the need for a good chemical, mechanical or thermal activators to enhance rapid hardening and strength development (Dreux 1995; Arjunan et al. 2001; Kim et al. 2002; Buchwald et al. 2003; Pacheco-Torgal et al. 2008; Bedard 2009). The search for a solution to this problem led us to the use of two techniques of alkaline chemical activation of cement object of the present study. The hardening phenomenon is normally accelerated by these agents crystallization that causes setting and hardening. The hydrate products result from the difference in solubility between bodies that disappear and those that are formed in the presence of water (Kjellsen, Detwiler 1992; Pacheco-Torgal et al. 2008a; Sedira et al. 2017).

The methods of determination of the normal consistency (the cone penetration test) and the setting time test (Vicat apparatus) are well adaptable for the mortar studied. The composition and constituents proportioning of the mortar also affect the setting time of cement paste and the development of hardening at young ages and at long term (Vénuat., 1969; Dreux., 1995).

It is reported that alkali activation is a highly active and rapidly developing field of activity in the global research and development community. Important needs for future research and development to support the optimal and appropriate utilization of alkali activated materials as a component of a sustainable future construction materials industry is identified (Roy 1999; John et al. 2015; Sedira et al. 2017).

When, no much research works are found in the literature on the use of local dune sand. Thus, the actual subject get its particularity by the use of dune sand in activated mortars as an important issue of investigation in regards to the main properties for experimental tested activated mortars at fresh and hardened state.

In this frame of idea, the main objective of the present study is to activate the hydraulic binder mortars based on dune sand and using a cement type CEM II/B grade 42.5 MPa. The chemical basic active agents as alkaline solutions of $\mathrm{NaOH}$ and $\mathrm{KOH}$ at dosages of 0,2 and $4 \%$ according to two molarity ( $2 \mathrm{M}$ and $4 \mathrm{M}$ ) were utilized.

\section{EXPERIMENTAL PROGRAM}

\subsection{CHARACTERIZATION AND IDENTIFICATION OF MATERIALS}

\section{Cement}

The hydraulic binder used is a blended Portland cement CEM II B / $42.5 \mathrm{MPa}$. Its specific density $\rho c=3.10 \mathrm{~kg} / 1$ and with a fineness of $4000 \mathrm{~cm}^{2} / \mathrm{g}$. the mineralogical and chemical composition is given in Table 1 as follows. 
Table 1. Chemical and mineralogical composition of the cement used

\begin{tabular}{|l|c|c|c|c|c|c|}
\hline \multicolumn{7}{|c|}{ Chemical composition } \\
\hline Constituents & $\mathrm{CaO}$ & $\mathrm{SiO}_{2}$ & $\mathrm{Al}_{2} \mathrm{O}_{3}$ & $\mathrm{Fe}_{2} \mathrm{O}_{3}$ & $\mathrm{MgO}$ & $\mathrm{Na}_{2} \mathrm{O}+\mathrm{K}_{2} \mathrm{O}$ \\
\hline Content (\%) & $62-67$ & $19-25$ & $2-9$ & $1-5$ & $0-1$ & $0-1.5$ \\
\hline \multicolumn{7}{|c|}{ Mineralogical composition } \\
\hline Constituents & Alite (C3S) & \multicolumn{2}{c|}{ Bélite (C2S) } & Célite (C3A) & Célite (C4AF) \\
\hline Content (\%) & $50-75$ & $7-30$ & $0-18$ & $4-20$ \\
\hline Average & 55 & 23 & 10 & 12 \\
\hline
\end{tabular}

\section{Dune sand}

The sand used in our study is a local siliceous dune sand from the Maiter river, M'sila region. The sand is of Aeolian origin, at least its fine grains rolled rounded shapes and with smooth surfaces. Thus, it is characterized by its fineness, the grading and its maximum diameter size that does not exceed $3.0 \mathrm{~mm}$. The properties of the tested sand are given in Table 2.

Table 2. Characteristics of dune sand used

\begin{tabular}{|c|c|c|c|c|c|}
\hline Property & $\begin{array}{c}\text { Density } \\
\mathrm{L} / \mathrm{C}(*) \\
\rho_{a} \\
\left(\mathrm{~g} / \mathrm{cm}^{3}\right)\end{array}$ & $\begin{array}{c}\text { Specific weight } \\
\rho_{s} \\
\left(\mathrm{~g} / \mathrm{cm}^{3}\right)\end{array}$ & $\begin{array}{c}\text { Porosity } \\
\text { L/C }{ }^{(*)} \\
(\%)\end{array}$ & $\begin{array}{c}\text { Sand } \\
\text { equivalent } \\
E_{s p} / E_{s v} \\
(\%)\end{array}$ & $\begin{array}{c}\text { Fineness } \\
\text { modulus } \\
\left(M_{f}\right)\end{array}$ \\
\hline Average & $1.64 / 1.72$ & 2.54 & $32.28 / 35.43$ & $75 / 80$ & 1.95 \\
\hline
\end{tabular}

${ }^{(*)} \mathrm{L}$ refers to loose state of the sand, $\mathrm{C}$ refers to compacted state of the sand.

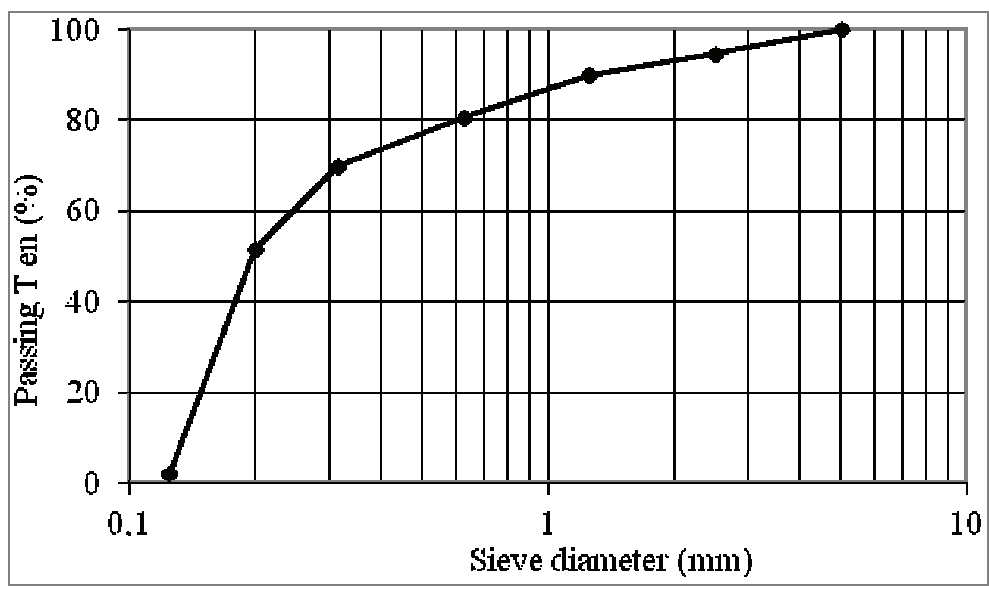

Fig. 1. Sieve analysis results of dune sand used 
The purpose of particle size analysis is to determine or define the grain size of aggregates and the percentage of grains of each size. The granulometric composition of aggregates is of great importance for the quality of concrete. Aggregates intended for concrete mixtures must be composed of grains of different sizes in order to ensure a minimum volume of voids.

The results of tests obtained are grouped in Fig. 1.

$$
M_{f}=\left[\Sigma\left(R_{i}\right)\right] / 100
$$

with $R_{i}$ - Percentage kept by the sieve (\%).

Regarding the above presented properties; it can be said that the sand is clean one with less silt fine impurities at optimal values $E_{s p}=75, E_{s v}=80$, and a finesse modulus $M_{f}$ equal to 1.96 which is a characteristic of fine dune sand (Table 2).

\section{Mixing water}

The amount of mixing water used for the batching of the mortars or concrete is much greater than that required for the complete hydration of the cement (which often would require only $25 \%$ of its weight. Indeed, water has two functions; it allows hydration also, it creates a sufficiently deformable medium to make possible ease of casting. It is this last condition which imposes the $\mathrm{W} / \mathrm{C}$ ratio according to the other parameters. The mixing water used for making concrete must be as pure as possible, it must not contain an excessive amount of silt, organic matter, acids, salts, sweeteners and other harmful impurities. The mixing water used in our study is a drinking tap water supplied by the civil engineering laboratory.

\section{Chemical activators}

The CEMII B/42.5 compound cement as hydraulic binder with a surface area of $4000 \mathrm{~cm}^{2} / \mathrm{g}$ is activated by two alkaline solutions, sodium hydroxide $(\mathrm{NaOH})$ and potassium hydroxide $(\mathrm{KOH})$ at different percentages 0,2 and $4 \%$ by varying the molarity of the basic solution from $2 \mathrm{M}$ to $4 \mathrm{M}$. These two types of solutions $(\mathrm{NaOH}$ and $\mathrm{KOH}$ ) have different densities for two molarities $(2 \mathrm{M})$ and $(4 \mathrm{M})$ at values of $(1.080,1.095)$ and $(1.115,1.118)$, respectively. They are prepared by adding a quantity of water to the concentrated compound in order to obtain the density of the solution used.

\subsection{PREPARATION OF MORTAR MIXTURES}

The mortar consists of an intimate mixture of cement and water that binds fine aggregates (sand). The mixture hardens thanks to a chemical reaction through a hydration process. The amount of mixing water added to the mixture must be sufficient to form a suitable plastic paste for the implementation and setting, the binder used is capable to hydrate in general not only in air but also in water medium (Vénuat 1969; Dreux 1995). 
The interest of use of the mortar in the laboratory is to measure the reactivity (normal consistency of the cement paste and setting of the cement) and the mechanical characteristics of the hydraulic binder and the hydrated compound products of the cement matrix (Dreux 1995).

The laboratory study is generally carried out on a standardized mortar of weight composition $(\mathrm{C} / \mathrm{S}=1 / 3)$ consisting of 3 parts of sand, 1 part of cement and water cement ratio $(\mathrm{W} / \mathrm{C}=0.55)$.

The $4 \times 4 \times 16 \mathrm{~cm}^{3}$ test prismatic specimens were made using the standardized mortar (fraction: $\mathrm{C} / \mathrm{S}=1 / 3$ ). The specimens were demolded and stored in water until the required age for flexural and compressive strength testing at different ages, 7, 14 and 28 days.

\section{RESULTS AND DISCUSSION}

\subsection{PROPERTIES AT THE FRESH STATE}

\subsubsection{SETTING TIME}

The setting of cement is generally slow, the addition of chemical activators and the further grinding of cement offer solutions to this phenomenon. Table 4 shows that the use of caustic alkalis $(\mathrm{NaOH}$ and $\mathrm{KOH})$ at different densities significantly improves the setting time.

Table 3. Properties of the various cements and mortars studied

\begin{tabular}{|l|c|c|c|c|c|}
\hline \multirow{2}{*}{ Mixtures designation } & \multicolumn{3}{|c|}{ Cements } & \multicolumn{2}{c|}{$\begin{array}{c}\text { Mortars } \\
(\mathrm{C} / \mathrm{S}=1 / 3)\end{array}$} \\
\cline { 2 - 6 } & $\begin{array}{c}\text { Temperature } \\
\left({ }^{\circ} \mathrm{C}\right)\end{array}$ & $\begin{array}{c}\text { Consistency } \\
(\%)\end{array}$ & $\begin{array}{c}\text { Initial } \\
\text { setting time }\end{array}$ & W/C & $\begin{array}{c}\text { Slump } \\
(\mathrm{cm})\end{array}$ \\
\hline $\begin{array}{l}\text { Control (without activator) } \\
(\mathrm{CM})\end{array}$ & 20 & 30 & $3 \mathrm{~h} 15 \mathrm{~min}$ & 0.55 & 4.0 \\
\hline $\begin{array}{l}\text { Activated mixtures } \\
\text { with } \mathrm{NaOH} \text { and } \mathrm{KOH}\end{array}$ & 20 & $25-28$ & $\begin{array}{c}3 \mathrm{~h} 00 \mathrm{~min} \\
\text { to 3 h } 05 \mathrm{~min}\end{array}$ & 0.55 & $3.5-4.0$ \\
\hline
\end{tabular}

\subsubsection{WORKABILITY}

The workability or consistency of mortar is the ability to sink under its own weight. This rheological characteristic of the fresh mortar must be controlled during the successive mixing and ensures the regularity of the amount of water used in the composition of the mortar. This property is expressed by the depth of penetration (in $\mathrm{cm}$ ) of a metal cone with a mass of 300 grams and having an angle of 30 degrees and the test results are presented in Table 3. 


\subsection{PROPERTIES AT THE HARDENED STATE}

\subsubsection{DENSITY}

Table 4 and Fig. 2 present the obtained results of the density for the different types of mortars studied.

Table 4. Results of the density for the different types of mortars studied

\begin{tabular}{|l|c|c|c|c|c|c|}
\hline Activation mode & $\begin{array}{c}\text { Mortars } \\
\text { mixtures }\end{array}$ & $\begin{array}{c}\text { Chemical } \\
\text { activator } \\
(\%)\end{array}$ & \multicolumn{4}{c|}{$\begin{array}{c}\text { Bulk. density } \rho \\
\text { at the age(days) } \\
\left(\mathrm{g} / \mathrm{cm}^{3}\right)\end{array}$} \\
\hline \multirow{3}{*}{ Age (days) } & & 1 & 7 & 14 & 28 \\
\hline $\begin{array}{l}\text { Control mortar } \\
\text { (without activator) }\end{array}$ & $\mathrm{CM}$ & 0 & 2.18 & 2.23 & 2.20 & 2.21 \\
\hline \multirow{5}{*}{ Chemical activation } & $\mathrm{M} 2 \mathrm{NaOH}^{*}$ & 2 & 2.18 & 2.22 & 2.21 & 2.22 \\
\cline { 2 - 7 } & $\mathrm{M} 2 \mathrm{NaOH}$ & 4 & 2.19 & 2.24 & 2.22 & 241 \\
\cline { 2 - 7 } & $\mathrm{M} 4 \mathrm{NaOH} * *$ & 2 & 2.21 & 2.25 & 2.23 & 2.25 \\
\cline { 2 - 7 } & $\mathrm{M} 4 \mathrm{NaOH}$ & 4 & 2.23 & 2.24 & 2.23 & 2.27 \\
\cline { 2 - 7 } & $\mathrm{M} 2 \mathrm{KOH}$ & 2 & 2.19 & 2.23 & 2.21 & 2.25 \\
\cline { 2 - 7 } & $\mathrm{M} 2 \mathrm{KOH}$ & 4 & 2.18 & 2.22 & 2.22 & 2.26 \\
\cline { 2 - 7 } & $\mathrm{M} 4 \mathrm{KOH}$ & 2 & 2.18 & 2.24 & 2.21 & 2.24 \\
\cline { 2 - 7 } & $\mathrm{M} 4 \mathrm{KOH}$ & 4 & 2.18 & 2.23 & 2.22 & 2.25 \\
\hline
\end{tabular}

* The index 2 refers to the mortars M2 with the molarity 2 ,

** The index 4 refers to the mortars M4 with the molarity 4.

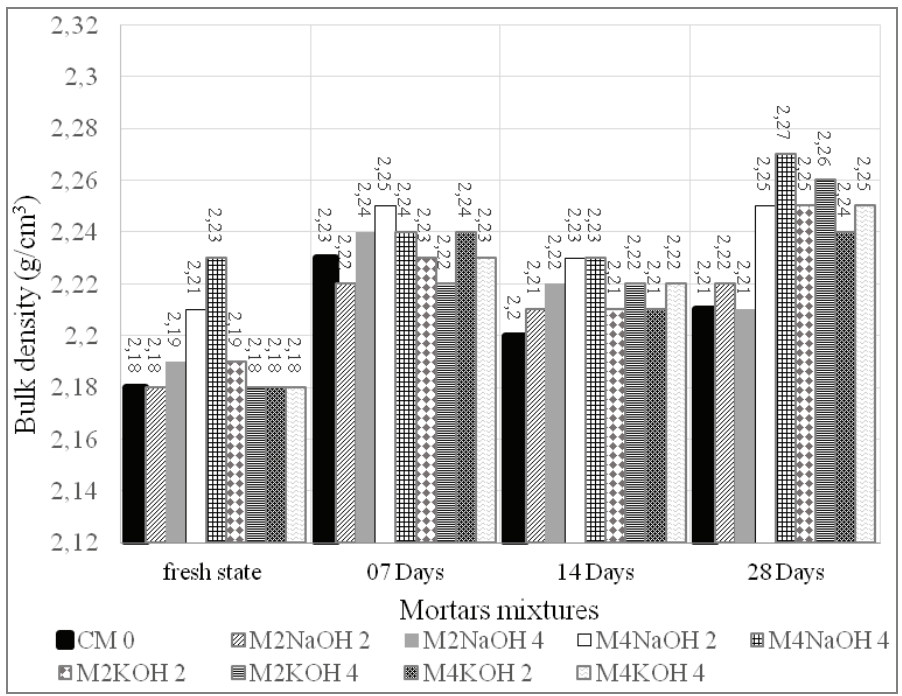

Fig. 2. The density evolution of the different studied mortars as a function of the age 
From Table 4 and Fig. 2 a significant increase in density over time for the mortars studied (activated and non-activated) during Periods I and II is noticed. This is due mainly to the hydration and absorption process. The analysis of the quantity of the absorbed water by the mortars specimens allows to draw the following conclusions.

A rapid absorption during the period I from 1 to 7 days, a roughly increased rate in density as a function of time, with values ranging from 2.18 to $2.25 \mathrm{~g} / \mathrm{cm}^{3}$. A smooth absorption development rate during the period II from 14 to 28 days, a slight increase in density of weighted specimens with values ranging from 2.21 to $2.26 \mathrm{~g} / \mathrm{cm}^{3}$.

\subsubsection{MECHANICAL RESPONSES (RC) AND (RT)}

In this study, it is considered necessary to discuss the experimental results obtained by analyzing the development of the mechanical response $R_{c}$ and $R_{t}$ tested specimen mortars as a function of the age 7,14 and 28 days.

The analysis of the mechanical response presented in the figures 3 and 4 as a function of the hardening age 7,14 and 28 days; these clearly show the normal increase of $R_{c}$ and $R_{t}$. This development is markedly faster at young age in the interval (0-7 days) than at matured state later till 28 days.

From the figures illustrating the variations of $R_{c}$ and $R_{t}$, it is found that the mechanical responses increase normally along the age of testing, regardless of the type of activation applied.

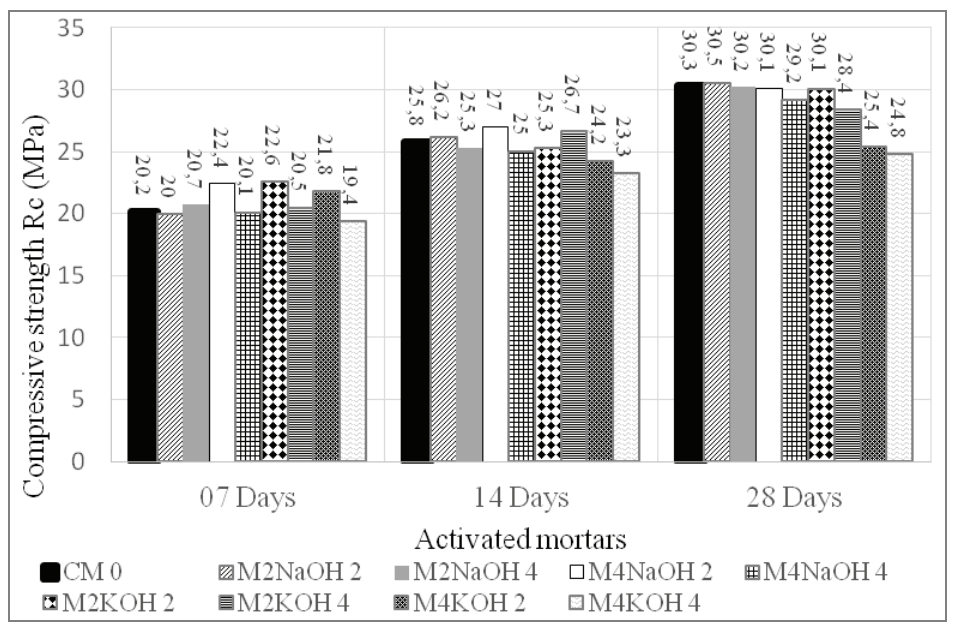

Fig. 3. Compressive strength development $\left(R_{c}\right)$ as a function of the age for studied mortars

This increase is greater for the chemically activated mortars compared to the control mix. The chemical activation directly influences the mechanical strength and the setting time of the binder, this is due to the presence of a higher $\mathrm{pH}$ equal to 12 which favors the dissolution of the constituents of the cement (the presence of a basic acti- 
vator influences directly on the solubility of the binder components), allowing the formation of stable hydrates and the formation of the structure of the paste (Ladjel et al. 2017). Alkaline activation is the most efficient method for enhancing cement hardenrnig and strength development. It is mainly referred to the activation by alkalis $(\mathrm{R}-\mathrm{OH})$ where the radical $\mathrm{R}$ presents ions of alkali metals $\left(\mathrm{Na}^{+}\right.$and $\left(\mathrm{K}^{+}\right)$(Fernández-Jiménez et al. 2006; Castro-Gomes et al. 2008; Saidat 2013). The increase in mechanical strength is reflected by the rise in $\mathrm{pH}$, hence the dissolution of the constituents of the cement and the formation of the structure from which the strengthening of the compressive and flexural resistances $\left(R_{c}, R_{t}\right)$. This is explained by the fact that the increase in mechanical strength results in an increase in $\mathrm{pH}$ and the startup of chemical reactions thereafter (Kjellsen, Detwiler 1992; Kim et al. 2002; Sedira et al. 2017). This is evident at early age at 7 days where the activated mortars register values of compressive strength superior to the reference one for almost all tested samples 23 and $20 \mathrm{MPa}$, respectively. Further, the major mortars with alkali $\mathrm{NaOH}$ activator gives similar strengths at 28 days compared to non activated specimens about $30 \mathrm{MPa}$. However, the $\mathrm{KOH}$ potassium mortars show lower mechanical responses decrease of around $20 \%$ compared to the reference mortar(without activator) and to $\mathrm{NaOH}$ based ones.

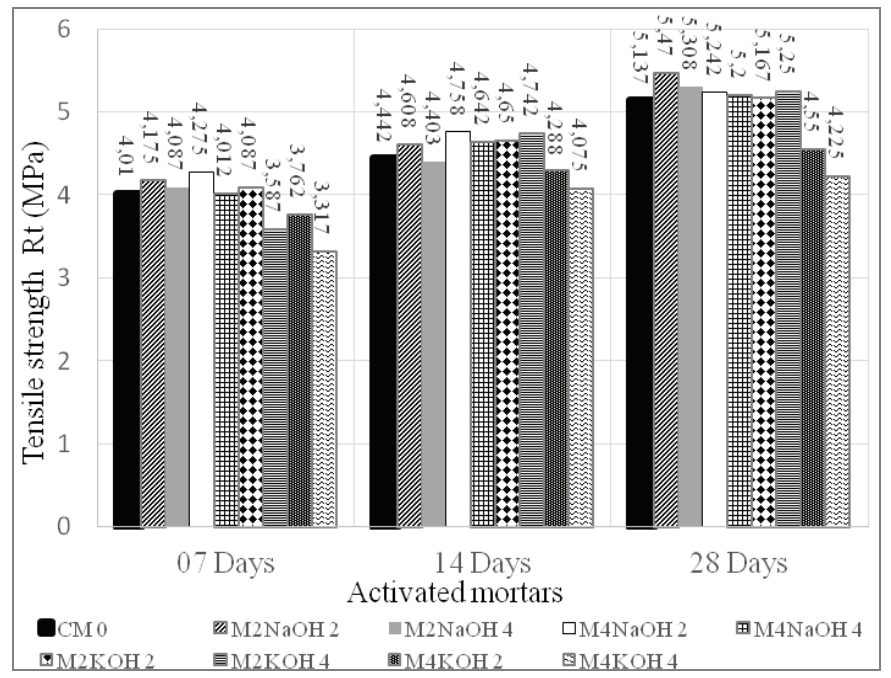

Fig. 4. Tensile strength development $\left(R_{t}\right)$ as a function of the age for studied mortars

The results obtained for the chemically activated mortars indicate that the best activator among those used is indeed sodium hydroxide (Figs. 3 and 4), despite the fact that the two chemical solutions used are with a very basicity and have $\mathrm{pH}$ values close to 14 . It is believed that this may be due to the fact of sodium hydroxide $(\mathrm{NaOH})$ that could be more electropositive (chemically) than potassium hydroxide $(\mathrm{KOH})$. 
The addition of the chemical activator $(\mathrm{NaOH})$ has the beneficial effect on the mechanical strengths (Rc, Rt) to be more important (this is due to the increase of the $\mathrm{pH}$ value which stabilizes the formation of $\mathrm{CSH}$ crystals) compared to the chemically activated mortar by the activator $(\mathrm{KOH})$ which does not contribute to the increase of the $\mathrm{pH}$ value because of its very low solubility.

From Figs. 3 and 4, it is noted that increasing the density ( $2 \mathrm{M}$ to $4 \mathrm{M})$ of sodium hydroxide and potassium lead to a reduction in mechanical strength $\left(R_{c}, R_{t}\right)$.

This finding suggests that increasing the density of sodium hydroxide $(\mathrm{NaOH})$ and potassium hydroxide $(\mathrm{KOH})$ contributes to decreasing the amount of calcium hydro silicates. On the other hand, the higher is the dosage $2 \%$ to $4 \%$ for the two alkaline solutions, the lower the values of the mechanical resistances $\left(R_{c}, R_{t}\right)$ (Fernandez et al. 2006). Increasing the density from $2 \mathrm{M}$ to $4 \mathrm{M}$ results in a low concentration of the solution, which slows down the rapid hydration of the cement and the evolution in mechanical strength $\left(R_{c}, R_{t}\right)$. This is because the hydraulic or hydraulic power of the cement increases when the lower density of the chemical solution is maintained (Fernández-Jiménez et al. 2006).

The activation of the cement by the sodium hydroxide used as a setting accelerator $t(\mathrm{NaOH})$ improves the setting time and gives higher mechanical strengths compared to the chemically activated potassium mortars by $(\mathrm{KOH})$ (Fernández-Jiménez et al. 2006; Pacheco-Torgal et al. 2008). The increase of the dosage of sodium hydroxide from 2 to $4 \%$ results in a reduction of the mechanical strengths $\left(R_{c}\right.$ and $\left.R_{t}\right)$ despite the increase in the density of the chemical activator. This could be explained by the fact that the increase in the quantity of sodium hydroxide leads to a more abundant presence of the hydroxide ions $\left(\mathrm{OH}^{-}\right)$which combined with the calcium ion $\left(\mathrm{Ca}^{++}\right)$ give calcium hydroxide $\left[\mathrm{Ca}(\mathrm{OH})_{2}\right]$. In addition, the excess of hydroxide ions $\left(\mathrm{OH}^{-}\right)$ creates an alkaline medium preventing the dissolution of the constituents of the cement (Ladjel et al. 2017; Sedira et al. 2017). A similar trend of mechanical responses is observed for mortars activated $\mathrm{NaOH}$ solution compared to potassium based agent. The latter, gives lower values of tensile strength in comparison with the reference mortar or those activated by the sodium hydroxide at average values of 4.2 and $5.2 \mathrm{MPa}$, respectively.

\section{CONCLUSION}

The analysis of the results obtained from the experimental study carried on chemical activated mortars based on local sand with $\mathrm{C} / \mathrm{S}=1 / 3$ and $\mathrm{W} / \mathrm{C}$ ratio equal to 0.55 allows the following conclusions to be drawn:

- A slight increase in the densities of studied mortars as a function of age of testing during periods I and II, this is due mainly to the hydration and absorption process. 
- The setting time of cement is generally slow, the addition of chemical activators presents solutions to overcome the handicap phenomenon.

- The use of caustic alkalis $(\mathrm{NaOH}$ and $\mathrm{KOH})$ at different densities significantly improves the setting time.

- The development of the compressive $\left(R_{c}\right)$ and tensile $\left(R_{t}\right)$ strengths according to the age of mortar demonstrates that the increase is much faster in the interval (0-7 days) than in the interval (7-28 days) regardless of the type of mortar tested. This rise is greater for the chemically activated compared to control reference mortar.

- Chemical activation has a direct influence on the mechanical strength and the setting time of the binder, this is due to the presence of a $\mathrm{pH}$ greater than or equal to 12 which favors the dissolution of the constituents of the cement (the presence of a basic activator directly influences the solubility of the binder components), allowing the formation of stable hydrates and the formation of the structure of the cement paste.

- The activation of the cement by the sodium hydroxide used as a setting accelerator $(\mathrm{NaOH})$ improves the setting time and gives higher mechanical strengths compared to the chemically activated potassic $(\mathrm{KOH})$ mortars.

\section{ACKNOWLEDGEMENTS}

The authors express their acknowledgement for any help provided by all person contributing in the preparation of the present work. Also, our thanks are extended to the staff members of the civil engineering department, university of M'sila for the technical support.

\section{REFERENCES}

ARJUNAN P., Silsbee M.R., ROY D.M., 2001, Chemical activation of low calcium flay ash. Part 1: Identification of suitable activators and their dosage. Proceeding of the international Ash utilization Symposium, Kentucky, 2001.

BARBARULO R., 2002, Comportement des Matériaux Cimentaires: actions des sulfates et de la température, Thèse de doctorat, Ecole Normale Supérieure de Cachan - Université de Laval, France.

BEDARD E., 2009, Influence de la température sur le comportement au jeune âge du béton, Thèse Université Laval, Canada.

BUCHWALD A., KAPS C., HOHMANN M., 2003, Alkali-activated binders and pozzolan cement binders-compete binder reaction or two sides of the same story, Alkali Activated Materials, State-of-theArt Report, RILEM TC 224-AAM.

CASTRO-GOMES J., PACHECO-TORGAL F, JALALI, 2008a, Alkali-activated binders: A review. Part 1. Historical background, terminology, reaction mechanisms and hydration products, Construction and Building Materials, 22, 1305-1314, http://doi.org/10.1016/j.conbuildmat.2007.10.015

DREUX G., 1995, Nouveau guide du béton, Editions Eyrolles, Paris 1995.

FERNÁNDEZ-JIMÉNEZ A., PALOMO A., CRIADO M., 2006, Alkali activated fly ash binders. A comparative study between sodium and potassium activators [Activación alcalina de cenizas volantes. 
Estudio comparativo entre activadores sódicos y potásicos], Materiales de Construcción, 56, 51-65. http://doi.org/10.3989/mc.2006.v56.i281.92

GALLUCCI E., ZHANG X., SCRIVENER K., 2006. Influence de la température sur le développement microstructural des bétons, Septième édition des journées scientifiques du regroupement francophone pour la recherche et la formation sur le béton.

JOHN L., PROVISA A., PALOMOB C.S., 2015, Advances in understanding alkali-activated materials, Cement and Concrete Research, Vol. 78, Part A, 110-125.

KJELLSEN K.O., DETWILER R.J., 1992, Reaction kinetics of portland cement mortars hydrated at different temperatures, Cement and Concrete Research, Vol. 22, 112-120.

KIM J.-K., HAN S.H., SONG Y.C., 2002, Effect of temperature and aging on the mechanical properties of concrete: Part I. Experimental results, Cement and Concrete Research, Vol. 32, 1087-1094.

LADJEL D., ZAIRI M., BELAGRAA L., 2017, Effet de l'activation chimique et thermique du ciment cem II B/42,5 sur la réponse mécanique d'un mortier, Proceeding of ICSMCE, 15-16 November 2017, Skikda, Algeria.

PACHECO-TORGAL F., CASTRO-GOMES J., JALALI S., 2008a, Alkali-activated binders: A review. Part 1, 2. Historical background, terminology, reaction mechanisms and hydration products, Construction and Building Materials, 22, 1305-1314, http://doi.org/10.1016/j.conbuildmat.2007.10.015

ROY D.M., 1999, Alkali-activated cements: Opportunities and challenges, Cement and Concrete Research, 29, 249-254, http://doi.org/10.1016/S0008-8846(98)00093-3

SAIDAT F., 2013, Activation chimique du métakaolin dans une matrice cimentaire, Thèse de Doctorat de l'université de Toulouse, Discipline ou spécialité: Génie Civil, Université Toulouse III - Paul Sabatier, France.

SEDIRA N., JOÃO C.G., GEDIMINAS K., XIANGMING Z., ALEXANDRE V., 2017, A review on mineral waste for chemical-activated binders: mineralogical and chemical characteristics, Mining Science, Vol. 24, 2017, 29-58.

VÉNUAT J.M., 1969, Ciments et bétons, Presses Universitaires de France, Paris, France.

VORNOVITCH L.V., DRON R., 1975, Action des différents activants sur l'hydratation du laitier granulé, Bull. Liaison Labo. P. ET Ch-83 - mai-juin 1975, Réf. 1810. 